\title{
$2253 E$
}

ZOOPLANKTON DATA

AND

SAMPLE ARCHIVE DATABASE DESIGN

FOR THE

DORSET RESEARCH CENTRE

JANUARY 1993

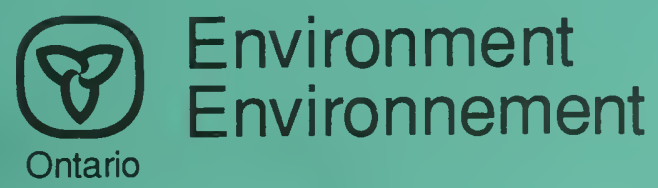





\section{ZOOPLANKTON DATA AND SAMPLE ARCHIVE \\ DATABASE DESIGN FOR \\ THE DORSET RESEARCH CENTRE}

\section{JANUARY 1993}

\section{$\oplus$}

Cette publication technique

n'est disponible qu'en anglais.

Copyright: Queen's Printer for Ontario, 1993

This publication may be reproduced for non-commercial purposes with appropriate attribution.

PIBS 2253 



\title{
ZOOPLANKTON DATA AND SAMPLE ARCHIVE DATABASE DESIGN FOR THE DORSET RESEARCH CENTRE
}

\author{
Report Prepared By: \\ T.W. Pawson \\ and \\ N.D. Yan
}

Ontario Ministry of the Environment Dorset Research Centre P.O. Box 39, Bellwood Acres Road Dorset, Ontario P0A 1E0

Canada 



\section{TABLE OF CONTENTS}

List of Tables $\ldots \ldots \ldots \ldots \ldots \ldots \ldots \ldots \ldots \ldots \ldots \ldots \ldots \ldots \ldots \ldots \ldots \ldots$ ii

List of Figures $\ldots \ldots \ldots \ldots \ldots \ldots \ldots \ldots \ldots \ldots \ldots \ldots \ldots \ldots \ldots \ldots$

Introduction $\ldots \ldots \ldots \ldots \ldots \ldots \ldots \ldots \ldots \ldots \ldots \ldots \ldots \ldots \ldots \ldots \ldots$

Overview of Database Design ......................... 3

The Zooplankton Database $\ldots \ldots \ldots \ldots \ldots \ldots \ldots \ldots \ldots \ldots \ldots \ldots \ldots \ldots \ldots$

Acknowledgements . ............................ 23

References ................................ 24 



\section{LIST OF TABLES}

Table 1 Summary of primary keys and foreign keys for the zooplankton database.

Table 2 Names and codes of taxa in the Z_TAXA table.

Table 3 Contents of the Z_CODE table (September 1992). 



\section{LIST OF FIGURES}

Figure 1 Master-detail relationship of the data tables. The single arrow head indicates the master table and the double, the detail table. The primary keys for these tables are listed in lower case letters. 



\section{INTRODUCTION}

Freshwater zooplankton are sensitive indicators of the loss of aquatic ecosystem integrity in the face of environmental stress, and its recovery following the removal of the stress (e.g., Keller et al. 1990, Keller and Yan 1991). In consequence, the Biological Studies Unit of the Limnology Section of the Ontario Ministry of the Environment's Water Resources Branch has assembled long-term descriptions of zooplankton communities from selected lakes in the Sudbury, Haliburton, Muskoka, Parry Sound and Nipissing areas of Ontario as part of three programmes - the Sudbury Environmental Study (SES, Anon. 1982), the Lakeshore Capacity Study (LCS, Dillon et al. 1984) and the Acid Precipitation in Ontario Study (APIOS, Anon. 1990). These records are unique in two ways. There is an unusually good reference lake data set, i.e., monthly collections for at least 1 year from 56 limnologically-diverse lakes. Secondly, there are unsually long records, $>10$ years, from 12 lakes. These data sets provide an excellent baseline description of zooplankton community structure and variability for Canadian Shield lakes, against which the detrimental impacts of future stressors and the benefical impacts of future regulatory or remedial actions can be assessed.

Because of the uniqueness and demonstrated value of these data, it is important that the samples are preserved, catalogued and maintained, that the sampling and enumeration protocols are documented and that the zooplankton database itself be clearly documented. In consequence, Yan et al. (1992) have described the construction and performance of the DRC (Dorset Research Centre) metered tow net, the collection gear routinely employed to collect zooplankton and Girard and Reid (1990) have described the zooplankton sampling schedules and sample enumeration protocols. The objective of this report is to describe the design of the zooplankton database - the electronic archive of the samples themselves and of the identification, enumeration and description of attributes of zooplankton species in samples. 
The zooplankton database was designed with the following objectives:

- to track the location of samples as they are transferred to and returned from contract enumerators,

- $\quad$ to record the exact location of samples in the Dorset sample library,

- $\quad$ to record a complete description of each sample, e.g., date of collection, sampling crew, collection gear and protocol, lake, station, sample volume, and compositing method,

- $\quad$ to record any permanent alterations of the samples, e.g., removal of animals for confirmatory identification or formation of composite samples,

- to record a complete description of all enumerations of samples, e.g., taxonomist, count date, count protocol, and count hardware,

- $\quad$ to record the lengths, identities and other attributes of all taxa examined during an enumeration of a sample,

- . to provide permanent records of all sampling gear employed, sampling sites visited, and zooplankton species encountered,

to facilitate the maintenance of data quality,

to record all alterations of the database, and

to facilitate the maintenance of and access to zooplankton data collected in past, present, and future programmes within the Section.

Several types of database models exist, but because of the huge size of the database (hundreds of thousands of individual measurements of animals), and the diversity of its design objectives, we selected a relational database management system as our model (Atre 1980). The database was produced and resides in tables managed by the ORACLE (Version 6) database management system. The tables are accessed via a local area network on an OS2 server.

The data that populate the database have been generated in two major ways. Prior to 1985 they were generated by conventional identification and counts of zooplankton aided by dissecting microscopy. The counts were written on log sheets, then keyed into spreadsheets, 
statistical, or other software packages as needed. Since 1985 the data have been generated by a custom written software package called ZEBRA (Zooplankton Enumeration and Biomass Routines for APIOS), a semi-automated program that facilitates the identification, enumeration, measurement, and demographic description of animals in the samples. This package had its origin in the work of Sprules et al. (1981).

It is not the objective of this report to introduce the reader to the advantages of relational databases. The interested reader can consult, for example, Atre (1980) or Date (1990) for such a discussion. Nor is it our purpose to promote our particular database design to other zooplankton ecologists. The interests of each investigator will certainly govern the design of his or her database. Our purpose is simply to document the DRC zooplankton database in detail for those who wish to use the data or examine the samples in the future. Because of the uniqueness of the sample collections and data, we assume there will be many such users in the future.

\section{OVERVIEW OF DATABASE DESIGN}

A relational dababase is perceived by its users simply as a collection of tables. Indeed the "relation" in "relational" is simply a mathematical term for a table (Date 1990). The zooplankton database consists of 17 tables. They can be grouped into three classes: Maintenance tables; Reference tables and Data tables. The five Maintenance tables (Z_REMOVE, Z_VOLUME, Z_COMPOSITE, Z_CHANGE and Z_NOMENCLATURE) document permanent alterations of the samples themselves or of any portion of the database. There are five Reference tables: $Z_{-}$GEAR, Z_LAKE, Z_TAXA, Z_ATT_ID, and Z_CODE. The first four tables record, respectively, descriptions of all sampling gear, lakes sampled, Ontario zooplankton species, and individual animal's attributes recorded during the counts. Each of these tables grows very slowly if at all. For example, the Z_TAXA table only grows if species new to the entire database are encountered. The last reference table, $Z_{-}$CODE, provides an explanation for all technician, protocol, hardware and flag 
codes scattered throughout the database. The entries for all columns with a title ending in "_CODE" are explained in this table.

The remaining seven tables comprise the zooplankton data themselves. These tables are hierarchically organized in what are termed master/detail relationships. Master and detail tables are associated in a simple manner. The detail table can contain more than one row of information associated with a single row in its master table. Consider the Z_SAMPLE Z_COUNT couplet as an example (Figure 1). Each row in Z_SAMPLE uniquely describes a sample, providing the lake sampled, sampling date, sampling gear, etc. Each of the rows in Z_COUNT describes a single, complete session of enumeration of one of the samples, providing a unique count identifier, the count protocol employed, the taxonomist's name, etc. Because a sample can be counted more than once, there may be more than one row in $Z_{-}$COUNT associated with a single row in Z_SAMPLE. In other words, Z_COUNT is a detail table of $Z_{-}$SAMPLE. The other master detail couplets are illustrated in Figure 1.

There are three detail tables of $Z_{-}$COUNT. Each row of Z_SUMMARY provides information about a single taxon in a count, for example, the numbers of that species counted, the subsample volume examined for that species, and its biomass and abundance. Z_DOMINANT_ROTIFER also provides a single row per taxon in the count; however, the only information provided is the identity and estimated rank abundance of rotifer taxa in the count. We have included this table in the database because this rotifer information is gathered during routine counts at little cost. At the end of a routine crustacean zooplankton count, the taxonomist spends a few additional minutes keying in the rotifer taxa observed and estimating their rank abundances. Z_ INDIVID is the last detail table of Z_COUNT. Each of its rows provides the identity and length of each uniquely numbered individual that was identified, counted and measured during the count.

The last two data tables are Z_ATTRIBUTE and Z_HAUL. Z_ATTRIBUTE is a detail table of $Z_{-}$INDIVID that records demographic data gathered during special zooplankton studies. Each of its rows provides attributes other than body length recorded for individuals 
examined during a count. For example, the taxonomist may have recorded the gender, numbers of eggs in a clutch, developmental stage, and body width of particular individuals

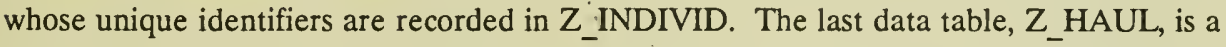
detail table of $Z$ _SAMPLE. It describes the individual hauls taken with the DRC plankton net whose combined contents form the composite samples that are enumerated.

Figure 1 Master-detail relationship of the data tables. The single arrow head indicates the master table and the double, the detail table. The primary keys for these tables are in listed lower case letters.

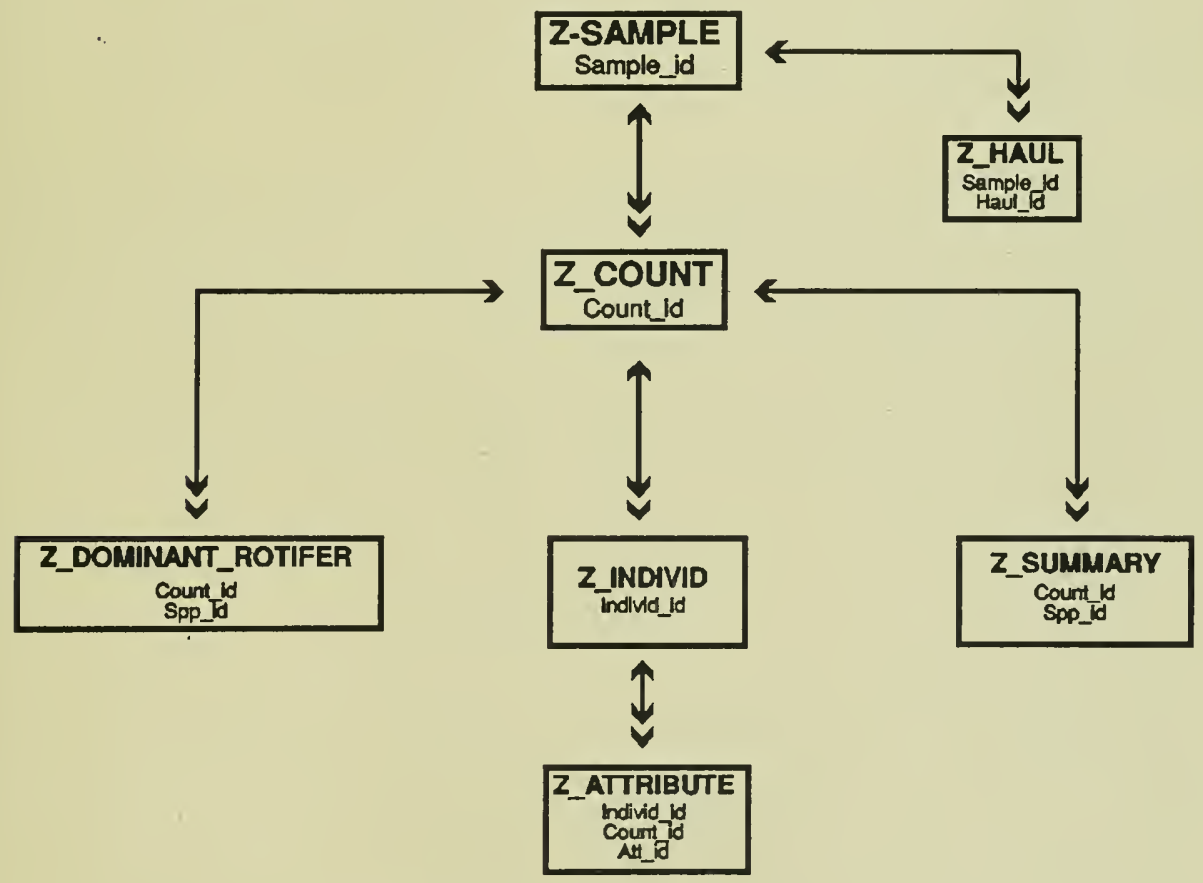


The lengths of the tables grow in a cascading fashion along the master/detail relationship hierarchy (Figure 1). For example, on average 300 samples are collected in a year; hence, Z SAMPLE will grow by about 300 rows a year. Roughly $10 \%$ of these sample will be counted twice for purposes of quality assurance, implying that Z_COUNT will grow by 330 rows a year. Because there are roughly 10 taxa of crustacean zooplankton identified in a standard count, roughly 3300 rows will be added to Z_SUMMARY each year. Assuming 250 individuals are counted and measured in each sample, 82,500 rows will be added to Z_INDIVID each year, i.e., 330 counts times 250 individuals. If two attributes other than length, e.g., gender and clutch size, are recorded for each individual counted, then Z_ATTRIBUTE would grow by 165,000 rows in the year, i.e., 2 attributes times 330 counts times 250 individuals. The size of the dataset provides a sufficient justification for the need for efficient organization of the data.

The use of the database is faciliated by the designation of primary and foreign keys. The former uniquely identify rows in a table, the latter provide linkages to other tables. These key columns are identified in Table 1 . The remainder of this section details the design of each table in the database. The order of presentation is Data tables, followed by Reference tables, and, finally, Maintenance tables. We conclude the report by providing the current contents of two of the reference tables, Z_TAXA (Table 2) and Z_CODE (Table 3). 
Table 1 Summary of primary keys and foreign keys for the zooplankton database.

\begin{tabular}{|c|c|c|c|c|}
\hline $\begin{array}{l}\text { TABLE } \\
\text { CODE }\end{array}$ & $\begin{array}{l}\text { SOURCE } \\
\text { TABLE }\end{array}$ & $\begin{array}{l}\text { PRIMARY } \\
\text { KEY(S) }\end{array}$ & $\begin{array}{l}\text { FOREIGN } \\
\text { KEYS }\end{array}$ & $\begin{array}{l}\text { DESTINATION } \\
\text { TABLE FOR } \\
\text { FOREIGN KEYS }\end{array}$ \\
\hline DI & Z_SAMPLE & SAMPLE_ID & $\begin{array}{l}\text { GEAR_ID } \\
\text { LAKE_ID }\end{array}$ & $\begin{array}{l}\text { Z_GEAR } \\
\text { Z_LAKE }\end{array}$ \\
\hline D2 & Z_HAUL & $\begin{array}{l}\text { (SAMPLE_ID, } \\
\text { HAUL_ID) }\end{array}$ & SAMPLE_ID & Z_SAMPLE \\
\hline D3 & Z_COUNT & COUNT_ID & SAMPLE_ID & Z_SAMPLE \\
\hline D4 & Z_SUMMARY & $\begin{array}{l}\text { (COUNT_ID, } \\
\text { SPP_ID) }\end{array}$ & $\begin{array}{l}\text { COUNT_ID } \\
\text { SPP_ID }\end{array}$ & $\begin{array}{l}\text { Z_COUNT } \\
\text { Z_TAXA }\end{array}$ \\
\hline D5 & Z_DOMINANT_ROTIFER & $\begin{array}{l}\text { (COUNT_ID, } \\
\text { SPP_ID) }\end{array}$ & $\begin{array}{l}\text { COUNT_ID } \\
\text { SPP_ID }\end{array}$ & $\begin{array}{l}\text { Z_COUNT } \\
\text { Z_TAXA }\end{array}$ \\
\hline D6 & Z_INDIVID & INDIVID_ID & $\begin{array}{l}\text { COUNT_ID } \\
\text { SPP_ID }\end{array}$ & $\begin{array}{l}\text { Z_COUNT } \\
\text { Z_TAXA }\end{array}$ \\
\hline D7 & Z_ATTRIBUTE & $\begin{array}{l}\text { (INDIVID_ID, } \\
\text { ATT_ID) }\end{array}$ & $\begin{array}{l}\text { INDIVID_ID } \\
\text { ATT_ID }\end{array}$ & $\begin{array}{l}\text { Z_INDIVID } \\
\text { Z_ATT_ID }\end{array}$ \\
\hline R1 & Z_GEAR & GEAR_ID & & \\
\hline R2 & Z_LAKE & LAKE_ID & & \\
\hline R3 & Z_TAXA & SPP_ID & & \\
\hline R4 & $\mathrm{Z}_{-}$ATT_ID & ATT_ID & & \\
\hline R5 & $Z_{-}$CODE & $\begin{array}{l}\text { (T_NAME, } \\
\text { PARAMETER, CODE }\end{array}$ & & \\
\hline M1 & Z_REMOVE & $\begin{array}{l}\text { (SAMPLE_ID, } \\
\text { SPP_ID, } \\
\text { ANIMAL_ID) }\end{array}$ & $\begin{array}{l}\text { SAMPLE_ID } \\
\text { SPP_ID }\end{array}$ & $\begin{array}{l}\text { Z_SAMPLE } \\
\text { Z_TAXA }\end{array}$ \\
\hline M2 & z_VOLUME & $\begin{array}{l}\text { (SAMPLE_ID, } \\
\text { ZDATE) }\end{array}$ & SAMPLE_ID & Z_SAMPLE \\
\hline M3 & Z_COMPOSITE & $\begin{array}{l}\text { (SAMPLE_ID, } \\
\text { CONTRIBUTOR_ID) }\end{array}$ & SAMPLE_ID & Z_SAMPLE \\
\hline M4 & Z_CHANGE & $\begin{array}{l}\text { (TNAME, KEY1, KEY } \\
\text { KEY3, PARAMETER, }\end{array}$ & , ZDATE) & \\
\hline M5 & Z_NOMENCLATURE & (SPPID_OLD, SPPID_I & NEW) & \\
\hline
\end{tabular}




\section{THE ZOOPLANKTON DATABASE}

\section{D1 Z_SAMPLE TABLE}

This table provides information about a particular sample, for example, where the sample was taken, when it was taken, how it was taken, who took it, and its location in the sample archive.

\begin{tabular}{lll}
$\#$ & COLUMN & DATA TYPE \\
\hline 1 & SAMPLE_ID & varchar (12) not null \\
2 & LAKE_ & varchar (20) not null \\
3 & STATION & varchar (11) not null \\
4 & LAKE_ID & varchar (4) not null \\
5 & ZDATE & date not null \\
6 & ZTIME & varchar (4) \\
7 & STN_NUM & varchar (9) \\
8 & COMP_STNS & number \\
9 & STYPE_CODE & varchar (5) \\
10 & DEPTH & number \\
11 & GEAR_ID & varchar (2) \\
12 & TECH_CODE & varchar (5) \\
13 & NUM_HAULS & number \\
14 & CAL_CNT & number \\
15 & CAL_TIME & varchar (5) \\
16 & VOLUME & number \\
17 & DRAWER & varchar (3) \\
18 & BOTTLE & varchar (7) \\
19 & LOC_CODE & varchar (5) \\
20 & XS_CODE & varchar (5) \\
21 & STUDY_CODE & varchar (5) \\
22 & VOLCALC_CODE & varchar (5) \\
23 & R_FLAG & varchar (1) \\
24 & L-FLAG & varchar (1) \\
25 & V_FLAG & varchar (1) \\
& &
\end{tabular}

SAMPLE_ID This is a unique identifier for each sample. Since 1980, SAMPLE ID for the routine DRC samples has been six characters long beginning with the letter Z. SAMPLE_ID is the Primary Key for this table.

LAKE

The name of the lake, excluding the word "LAKE". The column is constrained to accept upper case letters only. 
STATION

LAKE_ID

ZDATE

ZTIME

STN_NUM

COMP_STNS The number of stations in a composite sample.

STYPE_CODE The type of sample, e.g., composite. This column is keyed to the "Z_CODE" table.

DEPTH

GEAR_ID

TECH_CODE

NUM HAULS

CAL_CNT

CAL_TIME .

VOLUME

The DRC eleven digit code used to identify sampling stations in the "WATER" table. This is a foreign key to "W STATION". The "WATER" table is the database table containing all DRC lake and stream chemistry data. "W_STATION" is an associated table describing sampling locations.

The 4 character lake code assigned in ZEBRA, the custom counting software package. When two lakes have the same name and one or both have not been assigned STATION numbers, this code uniquely identifies the lake. This is a foreign key to Z_LAKE.

Contains the date on which the sample was taken. This column is in Oracle date format but does not contain the time.

The time at which the sample was taken. It is a four digit character field in the format "HHMM".

The name or number of the station where the sample was collected. This number is unique to the zooplankton programme, i.e., it is not in "W_STATION".

Depth (in metres) of discrete sample.

A code that keys to the "Z_GEAR" table. "Z_GEAR" supplies a complete description of the cōed gear.

Provides the abbreviated name of the person heading the crew that took the sample. This column is keyed to the "Z_CODE" table.

The number of hauls taken to form composite sample.

The calibration haul count for a composite formed from multiple hauls with a DRC plankton net (Yan et al. 1992). See Girard and Reid (1990) for description of haul strategies for composites.

The time (in seconds) required to pull the meter, used with a DRC plankton net, through the water column during the calibration haul.

The original volume (in litres) of lake water represented in the sample. 
Number of the file drawer containing the sample bottle in the DRC sample archive.

BOTTLE The code number of the bottle in the above named drawer. This number is not the same as the SAMPLE_ID.

LOC_CODE A code for the present location of the sample. The "Z_CODE" table explains this code.

XS_CODE Code for non-routine sample types to indicate that this particular sample should not be used in routine queries. The "Z_CODE" table provides details.

STUDY_CODE A code for the project for which this sample was taken, e.g., APIOS. This column is keyed to the "Z_CODE" table.

VOLCALC_CODE

A code to describe the method that was used to calculate the volume of the sample. Details are explained in the "Z_CODE" table.

R_FLAG

Flag to indicate that this sample is a routine DRC sample to be included in all regular data analysis. Upper case " $F "$ is used as a flag.

A_FLAG

Indicates that some animals have been removed. 'The "Z REMOVE" table provide details if the "A FLAG". is not null. " $F$ " is used as the flag.

V_FLAG

Indicates that volume has been removed to make a composite. The "Z_COMPOSITE" table provides details if the "V_FLAG" is not null. " $F^{-}$is used as the flag.

\section{D2 Z HAUL TABLE}

The $\mathrm{Z}$ HAUL table describes the tow net hauls used to form routine composite samples with a DRC plankton net (Yan et al. 1992).

\# COLUMN

1 SAMPLE ID

2 HAUL ID̄

3 TOW LENGTH

4 TOW $^{-}$CNT

5 TOW TIME

6 R_FLÄG
DATA TYPE

varchar (12) not null number not null

number

number

varchar (5)

varchar (1) 
SAMPLE_ID Sample identifier, keyed to the Z_SAMPLE table.

HAUL_ID Uniquely identifies the haul in this sample.

TOW_LENGTH The length (in metres) of this particular haul. It is assumed that the net was hauled vertically from this depth to the surface.

TOW_CNT The impeller reading from the DRC net associated with this HAUL_ID.

TOW_TIME The time (in sec.) taken to pull the meter and net through the water column for this haul.

R_FLAG Flag to indicate that this HAUL_ID should be included in routine queries. Upper case " $F$ " is used as the flag.

\section{D3 Z_COUNT TABLE}

The Z_COUNT table provides selected summary information from a single complete enumeration of a sample.

\begin{tabular}{lll} 
\# & COLUMN & DATA TYPE \\
\hline 1 & COUNT_ID & varchar (7) not null \\
2 & CNT_TYPE_CODE & varchar (5) \\
3 & CNT_SYSTEM_CODE & varchar (5) \\
4 & SAMPLE_ID & varchar (12) not null \\
5 & TECH_CODDE & varchar (5) \\
6 & ZDATE & date \\
7 & CNT_PRTCL_CODE & varchar (5) \\
8 & NUM_SPP & number \\
9 & NUM_INDIVID & number \\
10 & ROTIFER_INDEX_CODE & varchar (5) \\
11 & CNT_GRP_CODE & varchar(5) \\
12 & COMMENTS & varchar (20) \\
13 & R_FLAG & varchar (1) \\
14 & OMIT_CODE & varchar (5)
\end{tabular}

COUNT_ID

A unique code for each unique enumeration of a sample. Routinely, such an enumeration involves the identification, counting and measurement of 250 animals. "COUNT_ID" is the primary key for this table. 
CNT_TYPE_CODE

This code reports the class of enumeration that was performed on this sample, e.g., QA/QC. Explanation of codes are provided in the "Z_CODE" table.

\section{CNT_SYSTEM_CODE}

Code to describe the hardware that was used to execute the count of this sample, e.g., "Z2S1" could mean Zebra2 system, Sprules calipers \#1. The code is explained in the "Z_CODE" table.

SAMPLE_ID The unique code for this particular sample. This is keyed to the "Z_SAMPLE" table.

TECH_CODE Code identifying the technician who performed the enumeration. Details are found in the "Z_CODE" table.

ZDATE The date of this count. It does not include the time.

CNT_PRTCL_CODE

Identifies the counting protocol that was employed. Entries are explained in the "Z_CODE" table.

NUM_SPP The number of different taxa identified in this count of this sample.

NUM_INDIVID The total number of individuals that were counted.

ROTIFER_INDEX_CODE

Code for the relative abundance of rotifers in this count. Details are found in the "Z_CODE" table.

CNT_GRP_CODE

Identifies the group of organisms that were targeted in this enumeration of the sample, e.g., Rotifera and Crustacea. The codes are described in the "Z_CODE" table.

COMMENTS Comments recorded by the taxonomist concerning this count.

R_FLAG Flag to indicate that this count is one of the DRC's regular counts to be included in routine queries. An upper case "F" is used as the flag.

OMIT_CODE Entries indicate that there has been a problem with this particular count. The entries are explained in the "Z_CODE" table. 
The Z_SUMMARY table summarizes the data for each species found in each count.

\begin{tabular}{lll} 
\# & COLUMN & DATA TYPE \\
\hline 1 & COUNT_ID & varchar (7) not null \\
2 & SPP_ID & varchar (3) not null \\
3 & FA_ & number \\
4 & NUM_CT & number \\
5 & DENSITY & number \\
6 & BIOMASS & number \\
7 & NONZEB_WEIGHT & number \\
8 & W_CODE & varchar (5) \\
9 & SUML_ & number \\
10 & SUMW & number \\
11 & MINL & number \\
12 & MAXL & number \\
13 & A & number \\
14 & B & number \\
15 & LWR_CODE & varchar (5) \\
16 & R_FLAG & varchar (1)
\end{tabular}

COUNT_ID Key to the Z_COUNT table that uniquely identifies the count of this particular sample.

SPP_ID Species identification code as described in the Z_TAXA table.

FA

The fraction of the sample that was counted for this species. The value is required to calculate animal density or biomass, and $\begin{array}{llllllllllllll}\mathrm{m} & \mathrm{u} & \mathrm{s} & \mathrm{t} & \mathrm{b} & \mathrm{e} & > & 0 & \mathrm{a} & \mathrm{n} & \mathrm{d} \\ \mathrm{s} \text {. } & & & & & & & & & & & & \end{array}$

NUM_CT The number of animals of this species that was counted in the above fraction of the sample.

DENSITY The abundance of this taxon (in \#/m $\mathrm{m}^{3}$ ).

BIOMASS The biomass of this taxon (in $\mathrm{mg}$ dry weight $/ \mathrm{m}^{3}$ ).

NONZEB_WEIGHT

The mean individual weight (in $\mu \mathrm{g} \mathrm{dw}$ ) of this taxon. The source of this weight is provided by "W_CODE". 
W_CODE

SUML

SUMW

MINL

MAXL

A

B

LWR_CODE

R_FLAG
A code described in " $Z$ CODE" that explains the biomass calculation method, e.g., "ZEB" if the biomass was calculated from measurements of animals in the count.

The sum of the lengths (in $\mathrm{mm}$ ) of the measured animals.

The sum of the calculated dry weights (in $\mu \mathrm{g}$ ) of counted animals.

The minimum length check for this species. This is not the smallest animal encountered in the sample, rather it is a length used for QC purposes during the count.

The maximum length check for this species. This is not the largest animal encountered in the sample, rather it is a length used for QC purposes during the count.

The value of "a" in the length $(\mathrm{L})$ weight $(\mathrm{W})$ regression equation $\mathrm{W}=\mathrm{aL}$.

The value of "b" in the length $(\mathrm{L})$ weight $(\mathrm{W})$ regression equation $\mathrm{W}=\mathrm{a} \mathrm{L}^{\mathrm{b}}$.

A code that keys back to the "Z_CODE" table providing the source of that length (L) weight $(\mathrm{W})$ regression equation.

The flag to indicate that the data for this taxon are to be included in routine queries. The upper case character " $F$ " is used as the flag.

\section{D5 Z_DOMINANT_ROTIFER TABLE}

The Z_DOMINANT_ROTIFER table provides the estimated rank abundance of the rotifers observed in a count of a sample.

\# COLUMN

1 COUNT_ID

2 SPP ID

3 TAXXN_RANK
DATA TYPE

varchar (7) not null

varchar (3) not null

number

COUNT_ID Key to the "Z_COUNT" table that uniquely identifies the count of this particular sample. The sample is described in the "Z_SAMPLE" table.

SPP_ID Species identification code from the Z_TAXA table. 
TAXON_RANK A rank for this species in this count, "1" indicating the most abundant taxon.

\section{D6 Z_INDIVID TABLE}

The Z_INDIVID table contains the individual animal's measured lengths.

\begin{tabular}{lll} 
\# & COLUMN & DATA TYPE \\
\hline 1 & INDIVID ID & number not null \\
2 & COUNT ID & varchar (7) not null \\
3 & SPP ID & varchar (3) \\
4 & LENGTH & number \\
5 & R_FLAG & varchar (1)
\end{tabular}

INDIVID_ID An identification number that, together with "COUNT_ID", uniquely identifies an individual animal.

COUNT_ID Key to the "Z_COUNT" table that uniquely identifies the count of this particular sample.

SPP_ID Taxon identification number. This is keyed to the "Z-TAXA" table.

LENGTH The measured length of the animal (in $\mathrm{mm}$ ).

R_FLAG Flag to indicate that individual should be included in routine queries. Upper case " $F$ " is the flag.

\section{D7 Z_ATTRIBUTE TABLE}

The Z_ATTRIBUTE table provides a flexible means of recording attributes, other than body lengths, of each individual animal. The "Z_ATT _ ID" table (number R4) provides the details for each attribute code (ATT_ID).

\begin{tabular}{lll} 
\# & COLUMN & DATA TYPE \\
\hline 1 & INDIVID_ID & number not null \\
2 & COUNT_ID & varchar(7) not null \\
3 & ATT_ID & varchar (4) not null \\
4 & ATT_VAL & varchar (20)
\end{tabular}


INDIVID_ID An identification number that, together with "COUNT_ID", uniquely identifies an individual animal that was measured.

COUNT_ID Key to the "Z_COUNT" table that uniquely identifies the count of this particular sample.

ATT_ID Unique key to the "Z_ATT_ID" table that identifies a particular attribute, e.g., \# of eggs, or length of a body part.

ATT_VAL The entry for this attribute. Units are provided in the "Description" column in "Z_ATT_ID", where applicable.

\section{R1 Z_GEAR TABLE}

The Z_GEAR table describes all of the zooplankton sampling gear used by the DRC since it began collecting zooplankton during the Sudbury Environment Study in 1973.

\begin{tabular}{lll} 
\# & COLUMN & DATA TYPE \\
\hline 1 & GEAR_ID & varchar (2) not null \\
2 & TYPE_CODE & varchar (5) \\
3 & DESCRIPTION & varchar (35) \\
4 & MESH & number \\
5 & DIAMETER & number \\
6 & AREA & number \\
7 & VOLUME & number \\
8 & COMMENTS & varchar (65)
\end{tabular}

GEAR_ID A code assigned to a particular sampling gear.

TYPE_CODE A descriptive code the tells the user if the gear was a net, Schindler/Patalas trap, etc. The "Z_CODE" table explains the codes.

DESCRIPTION A description of the gear, e.g., closing conical metered net.

MESH The aperture size (in $\mu \mathrm{m}$ ) of the filtering mesh portion of the apparatus.

DIAMETER The inside diameter (in $\mathrm{cm}$ ) of the mouth of a net-type apparatus. The column is null if the gear is not a net. Nets are assumed to have circular mouths.

AREA The area (in $\left.\mathrm{m}^{2}\right)$ of the mouth of a net. 
VOLUME The volume (in litres) of a fixed volume sampler, e.g., a Schindler/Patalas trap.

COMMENTS Descriptive comments, such as where and when the gear was used.

\section{R2 Z_LAKE TABLE}

The Z LAKE table contains a list of all the lakes and locations from which the DRC has collected samples of zooplankton.

\begin{tabular}{lll} 
\# & COLUMN & DATA TYPE \\
\hline 1 & LAKE & varchar (20) not null \\
2 & STATION & varchar (11) \\
3 & LAKE ID & varchar (4) \\
4 & EASTING & number \\
5 & NORTHING & number
\end{tabular}

LAKE The name of the lake without the extension "lake". The column is constrained to accept only upper case letters.

STATION The standard DRC eleven digit code used in the "WATER" table. This a foreign key to "W_STATION".

LAKE_ID The 4 character lake code used by ZEBRA, the custom counting software package employed by the DRC.

EASTING The geographic easting grid reference in the Universal Transverse Mercator Grid System (UTM).

NORTHING The geographic northing grid reference in the Universal Transverse Mercator Grid System (UTM).

\section{R3 Z_TAXA TABLE}

The $Z_{-}$TAXA table provides the scientific name and coded identifier for all the zooplankton taxa in the database.

\# COLUMN

1 SPP ID

2 SPP_ABBREV
DATA TYPE

varchar (3) not null

varchar(10) 
SPP_ID The 3 digit numeric code for taxa that is used throughout the database. The 100, 200 and 300 series are reserved for Cladocera, Calanoida and Cyclopoida, respectively. The 400 and 500 series are reserved for Rotifera and the 600 series for macrozooplankton such as larval Chaoborus. The 700 series records miscellaneous taxa such as macroalgae.

SPP_ABBREV An abbreviated name of the taxon, e.g., B. long. = Bosmina longirostris.

SPP NAME Full scientific name (Latin binomial) with authority for each taxon.

T_FLAG

To indicate if the nomenclature has been changed over time, an upper case " $F$ " is used as the flag.

\section{R4 Z_ATT_ID TABLE}

The Z_ATT_ID table provides a detailed description of the attribute codes.

\begin{tabular}{lll} 
\# & COLUMN & DATA TYPE \\
\hline 1 & ATT_ID & varchar (4) not null \\
2 & ATT_TYPE & varchar (1) \\
3 & DESCRIPTION & varchar (20)
\end{tabular}

ATT_ID A unique code for the assigned attribute.

ATT_TYPE The attribute type: $\mathrm{C}$ (character), $\mathrm{N}$ (numeric), $\mathrm{T}$ (tabled) or $\mathrm{M}$ (measurement). Type $\mathrm{C}$ is a character string. Type $\mathrm{N}$ will generally be a count, e.g., 4 eggs. Type $T$ represents a character string where all possible values can be prespecified, e.g., male or female gender. Type $\mathrm{M}$ represents a measurement of some body part other than total length.

DESCRIPTION Brief description of the attribute and, where appropiate, its units.

\section{R5 Z_CODE TABLE}

The "Z_CODE" table (see Table 3) provides the user with a flexible and efficient means of defining the codes used throughout all of the database tables. We have used the convention of ending a column name with "_CODE" to indicate that all possible entries in this column 
are explained in this table.

\begin{tabular}{lll} 
\# & COLUMN & DATA TYPE \\
\hline 1 & T NAME & varchar (20) not null \\
2 & PARAMETER & varchar (20) not null \\
3 & CODE & varchar (5) not null \\
4 & DESCRIPTION & varchar (60)
\end{tabular}

T_NAME The name of the table containing the code.

PARAMETER The column in the above table containing the code.

CODE The code used. It must be unique and five or less characters in length.

DESCRIPTION A detailed explanation of the code.

\section{M1 Z_REMOVE TABLE}

The Z_REMOVE table records the permanent removal of any animals from samples, for example, for shipment to other researchers in collaborative work.

\begin{tabular}{lll} 
\# & COLUMN & DATA TYPE \\
\hline 1 & SAMPLE_ID & varchar (12) not null \\
2 & SPP ID & varchar (3) not null \\
3 & ANIMAL_ID & number not null \\
4 & LENGTH & number \\
5 & ZDATE & date \\
6 & TECH_CODE & varchar (5) \\
7 & COMMENTS & varchar (20)
\end{tabular}

SAMPLE_ID The unique sample identifier code, keyed to the Z_SAMPLE table.

SPP_ID Species identification code described in the Z_TAXA table.

ANIMAL_ID A unique identification number for the animal that was removed from the sample. There is no relation between this column and "INDIVID_ID" in the "Z_INDIVID" table.

LENGTH The length (in mm) of the removed animal.

ZDATE The date the animal was removed. 
TECH_CODE The code for the technician that removed the animal. The code is explained in the "Z_CODE" table.

COMMENTS The reason that the animal was removed.

\section{M2 Z_VOLUME TABLE}

The Z VOLUME table documents the permanent removal of partial volumes from a sample, e.g., to create a composite sample. A flag will the added to "V_FLAG" in the "Z_SAMPLE" table when this is done.

\begin{tabular}{lll} 
\# & COLUMN & DATA TYPE \\
\hline 1 & SAMPLE_ID & varchar (12) not null \\
2 & ZDATE & date not null \\
3 & TECH_CODE & varchar (5) \\
4 & NEW_VOLUME & number \\
5 & TECHNIQUE_CODE & varchar (5)
\end{tabular}

SAMPLE_ID The unique sample identifying code, keyed to the Z_SAMPLE table.

ZDATE The date the sample was manipulated.

TECH_CODE The code for the technician that removed the partial volume. The technician's name will be found in the "Z_CODE" table.

NEW_VOLUME

The new, final volume of the sample (in litres).

TECHNIQUE_CODE

A code for the technique used to manipulate the sample. Details will be found in "Z_CODE".

\section{M3 Z_COMPOSITE TABLE}

This table documents the removal of a fraction of a sample to produce a composite.

\begin{tabular}{ll}
$\#$ & COLUMN \\
\hline 1 & SAMPLE_ID \\
2 & CONTRIBUTOR_ID \\
3 & C_PERCENT
\end{tabular}

DATA TYPE

varchar (12) not null

varchar (12) not null

number not null 
SAMPLE_ID The sample identification code of the new composite sample being produced.

CONTRIBUTOR_ID

The sample identification code of the sample contributing volume to the new composite sample.

C_PERCENT The percent of the new composite sample donated by the contributor.

\section{M4 Z_CHANGE TABLE}

The Z CHANGE table documents all updates (editing) of the database. Because some tables have more then one primary key, "KEY1", "KEY2" and ,"KEY3" refer to the primary keys of a particular table (TNAME) that uniquely identify a row in that table.

\begin{tabular}{lll} 
\# & COLUMN & DATA TYPE \\
\hline 1 & TNAME & varchar (20) not null \\
2 & KEY1 & varchar (20) not null \\
3 & KEY2 & varchar (20) not null \\
4 & KEY3 & varchar (20) not null \\
5 & PARAMETER & varchar (20) not null \\
6 & TECH_CODE & varchar (5) \\
7 & ZDATE & date \\
8 & OLD_VALUE & varchar (5) \\
9 & NEW_VALUE & varchar (5) \\
10 & COMMENTS & varchar (25)
\end{tabular}

TNAME Name of table that was updated.

KEY1

KEY2

KEY3

The three key columns refer to the primary columns of the table which is being updated. The number of non-null entries in these three KEYs will equal the number of primary key columns in the table.

PARAMETER The name of the column being updated.

TECH_CODE A character code identifying the database manager that performed the update. The code is explained in the "Z_CODE" table.

ZDATE

The date on which the update was made. 
OLD_VALUE The value being replaced.

NEW_VALUE The new value.

COMMENTS A brief description of the justification for changing the value or an indication of the source of the change.

\section{M5 Z_NOMENCLATURE}

This is a table that records any changes in names of taxa. These changes could represent new species, changes in names of existing species, combinations of species, or separation of old species into several new species.

\begin{tabular}{lll} 
\# & COLUMN & DATA TYPE \\
\hline 1 & ZDATE & date not null \\
2 & CHNG_CODE & varchar (5) \\
3 & SPPID_OLD & number not null \\
4 & SPPID_NEW & number not null \\
5 & CITATION & varchar $(50)$ \\
6 & COMMENTS & varchar $(100)$
\end{tabular}

ZDATE The date on which the new nomenclature was incorporated into the routine counting protocol.

CHNG_CODE The type of change, i.e., a new species, a renaming of an old species, or a lumping together or splitting of old species. The codes are explained in the Z_CODE table.

SPPID_OLD The old 3 digit species identification code. See Z_TAXA for details.

SPPID_NEW The new 3 digit species identification code. See Z_TAXA for details.

CITATION The reference (first author, date, journal, volume and page) that justifies the change in nomenclature.

COMMENTS A comment on the change. 


\section{ACKNOWLEDGEMENTS}

We thank Bruce LaZerte and Martyn Futter for advice on database design and René Morrison for her patience at the wordprocessor. 


\section{REFERENCES}

Anon. 1982. Sudbury Environmental Study: Studies of lakes and watersheds near Sudubry Ontario: final limnological report. Ont. Min. Envir., Water Resources Branch, Limnology Section report SES 009/82, 689 pp.

Anon. 1990. Acidic precipitation in Ontario Study (APIOS) - annual program report 1988/1989. Ont. Min. Envir., APIOS co-ordination office report, 94 pp.

Atre, S. 1980. Data Base: Structured Techniques for Design, Performance, and Management with Cases Studies. John Wiley \& Sons. New York. 442 pp.

Date, C.J. 1990. An introduction to database systems. Volume 1. Addison-Wesley Publishing Company, Reading, Mass. 854 pp.

Dillon, P.J., K.H. Nicholls, W.A. Scheider, N.D. Yan and D.S. Jeffries. 1986. Lakeshore Capacity Study: Trophic Status., Ministry of Municipal Affairs, Research and Special Projects Branch report, 89 pp.

Girard, R. and R.A. Reid. 1990. Dorset Research Centre lakes: sampling methodology (1986-1989) and lake morphometry. Ont. Min. Envir. Data Report DR 90/4.

Keller, W. and N.D. Yan. 1991. Recovery of crustacean zooplankton species richness in Sudbury area lakes following water quality improvements. Can. J. Fish. Aquat. Sci. 48: $1635-1644$.

Keller, W., N.D. Yan, K.E. Holtze and J.R. Pitblado. 1990. Inferred effects of lake acidification on Daphnia galeata mendotae. Envir. Sci. Technol. 24: 1259-1261.

Sprules, W.G., L.B. Holtby and G. Griggs. 1981. A microcomputer-based measuring device for biological research. Can. J. Zool. 59: 1611-1614.

Yan, N.D., D.J. McQueen, T.W. Pawson, R. Girard and V. Visman. 1992. Measuring zooplankton net filtration efficiency in Dorset lakes. Ont. Min. Envir. Tech. Report $15 \mathrm{pp}$. 
Table 2 Names and codes of taxa in the Z_TAXA table.

\begin{tabular}{|c|c|c|}
\hline SPECIES_ID & SPECIES_ABBREV & SPECIES_NAME \\
\hline 101 & ACA CURV & Acantholeberis curvirostris \\
\hline 102 & ACR HARP & Acropenus harpae \\
\hline 103 & ALO AFFI & Alona affinis \\
\hline 104 & ALO COST & Alona costata \\
\hline 105 & ALO GUTT & Alona guttata \\
\hline 106 & ALO INTE & Alona intermedia \\
\hline 107 & ALO QUAD & Alona quadrangularis \\
\hline 108 & ALO RECT & Alona rectangula \\
\hline 109 & ALO SP & Alona sp. \\
\hline 110 & BOS LONG & Bosmina longirostris \\
\hline 111 & CER LAC & Ceriodaphnia lacustris \\
\hline 112 & CER MEG & Ceriodaplinia megalops \\
\hline 113 & CER PUL & Ceriodaphnia pulchella \\
\hline 114 & CER RETIC & Ceriodaphnia reticulata \\
\hline 115 & CER SP & Ceriodaphnia sp. \\
\hline 116 & CHY BIC & Chydonis bicomutus \\
\hline 117 & CHY PIG & Chydorus piger \\
\hline 118 & CHY SPHA & Chydoris sphaericus \\
\hline 119 & DAP AMB & Daphnia anıbigua \\
\hline 120 & DAP CAT & Daphnia catawba \\
\hline 121 & DAP DUB & Daphnia dubia \\
\hline 122 & DAP G ME & Daplınia galeata mendotae \\
\hline 123 & DAP LONG & Daphnia longiremis \\
\hline 124 & DAP PUL & Daphnia pulicaria \\
\hline 125 & DAP PARV & Daphnia parvula \\
\hline 126 & DAP PUL & Daphnia pulex \\
\hline 127 & DAP RETR & Dap/nia retrocurva \\
\hline 128 & DAP ROS & Daphnia rosea \\
\hline 129 & DAP SCHO & Daphnia schodleri \\
\hline 130 & DLA BRAC & Diaphanosoma brachyunum \\
\hline 131 & DIA LEU & Diaphanosoma leuchtenbergianum \\
\hline 132 & EUB COR & Eubosmina corcgoni \\
\hline 133 & EUB TUB & Eubosmina tubicen \\
\hline 134 & EUR LAM & Eurycercus lamellatus \\
\hline 135 & HOL GIBB & Holopedium gibberum \\
\hline
\end{tabular}


Table 2 (cont'd.)

136

137

138

139

140

141

142

143

144

145

146

147

148

149

150

151

152

153

155

156

160

161

162

163

164

165

166

167

168

169

170

171

172

173
ILY SPIN

LAT SET

LEP KIN

MAC LAT

OPH GRAC

PLE HAMU

POL PED

SCA AURI

SCA KIN

SID CRYS

SIM SERR

SIM VETU

STR SERR

BYT CEDE

EUB LONG

CER QUAD

DIA BIRG

CHY GLOB

AL ACUT

EUB SP

ACAN SP

ACROP

ALONEL

ANCHIS

BOS SP

BYTHO SP

CAMPTO

CHY SP

DAP SP

DIA SP

EURYC SP

EUB SP

GRAP SP

HOL SP
Ilyocryptus spinifer

Latona setifera

Leptodora kindtii

Macrothrix laticomis

Ophryoxus gracilis

Pleuroxus hamulatus

Polyphenus pediculus

Scapholeberis aurita

Scapholeberis kingi

Sida crystallina

Simocephalus serrulatus

Simocephalus vetulus

Streblocercus serricaudatus

Bythotrephes cederstroemi

Eubosmina longispina

Ceriodaphnia quadrangula

Diaphanosoma birgei

Chydonus globosus

Alonella acutirostris

Eubosmina sp.

Acantholeberis sp.

Acroperus sp.

Alonella sp.

Anchistropus sp.

Bosmina sp.

Bythotrephes sp.

Camptocercus sp.

Chydoris sp.

Daphnia sp.

Diaphanosoma sp.

Eurycercus sp.

Eubosmina sp.

Graptoleberis sp.

Holopedium sp. 
Table 2 (cont'd.)

174

175

176

177

178

179

180

181

182

183

184

185

186

187

199

201

202

203

204

205

206

207

208

209

210

211

212

213

214

215

216

217

218

219
ILY SP

KUR SP

LATON SP

LEPTO SP

MACROTH

OPHR SP

OXY SP

PLEU SP

POLYP SP

PSEUD SP

SCAP SP

SIDA SP

SIMOC SP

DAP MIDD

UNID CLAD

CAL COP

LEPTO ASHL

AGLA LEPT

LEPTO MIN

SKIS OREG

SKIS REIG

ONY SANG

LEPTO SICI

LEP SICILO

EPI LAC

E LAC CO

LIM MACR

SEN CALA

S CAL CO

CAL NAUP

SE CA NAU

DI STAG

LI MA COP

LI MA NAU
Ilyocrytus sp.

Kurzia sp.

Latona sp.

Leptodora sp.

Macrothrix sp.

Ophryoxus sp.

Oxyurella sp.

Pleuroxus sp.

Polyphemus sp.

Pseudochydoris sp.

Scapholeberis sp.

Sida sp.

Simocephalus $s p$.

Daphınia middendorffiana

Unidentified Cladoceran

Calanoid copepodid

Leptodiaptomus ashlandi

Aglaodiaptomus leptopus.

Leptodiaptomus minutus

Skistodiaptonus oregonensis

Skistodiaptomus reighardi

Onychodiaptomus sanguincus

Leptodiaptomus sicilis

Leptodiaptomus siciloides

Epischura lacustris

Epischura lacustris copepodid

Linunocalanus macrunis

Senecella calanoides

Senecella calanoides copepodid

Calanoid nauplius

Senecella calanoides nauplius

Diaptomus stagnalis

Limnocalanus macrurus copepodid

Limnocalanus macrurus nauplius 
Table 2 (cont'd.)

\section{SPECIES_ID SPECIES_ABBREV}

\section{SPECIES_NAME}

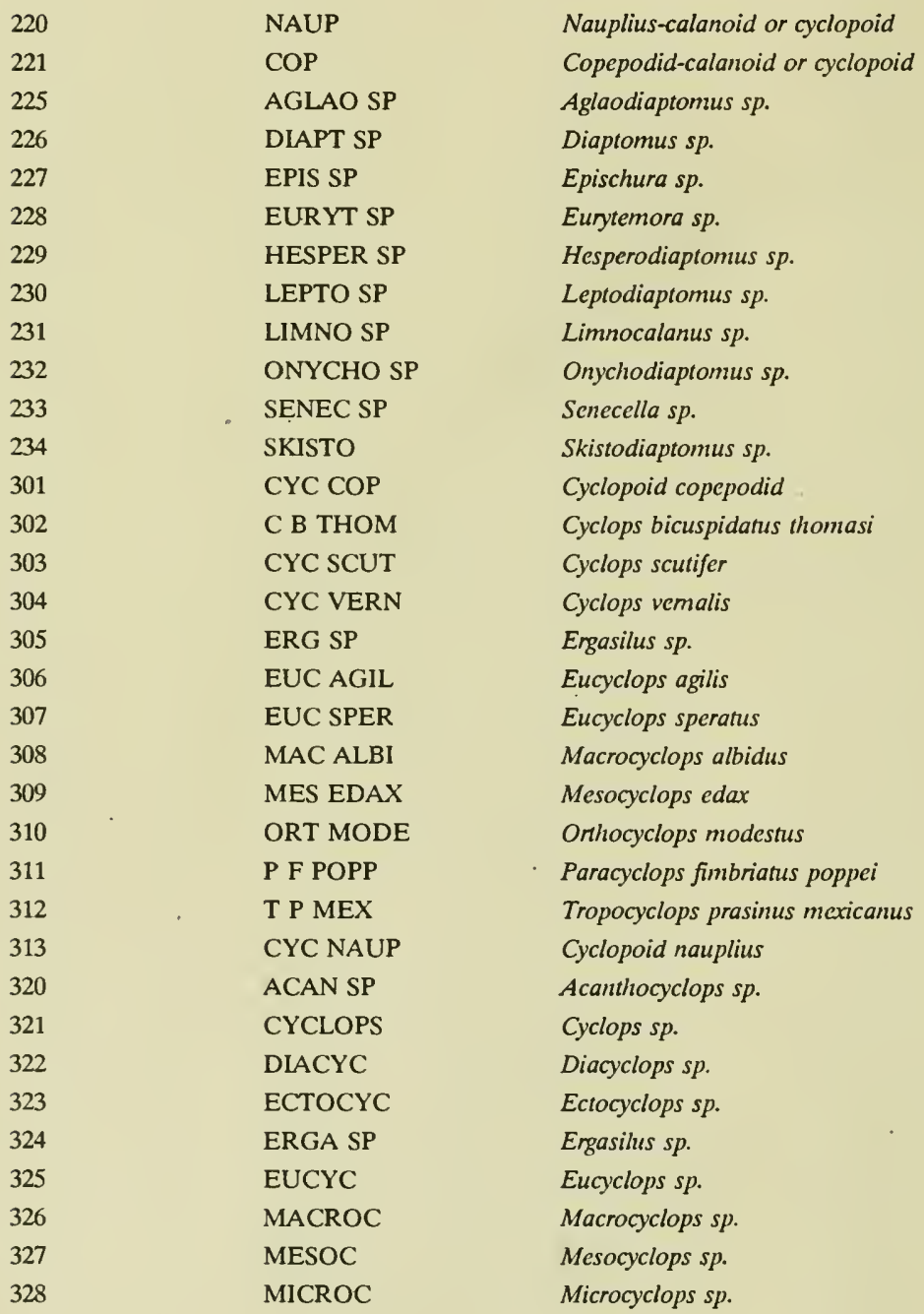


Table 2 (cont'd.)

\section{SPECIES_ID SPECIES_ABBREV SPECIES_NAME}

329

330

331

332

333

334

335

336

337

338

339

340

341

342

343

401

501

502

503

504

505

506

507

508

509

510

511

512

513

514

515

516

517

518
ORTHOC

PARAC

TROPOC

ECTO POLY

EUC SERR

EUC NEOM

E. M DENT

EUC PRIO

T P PRAS

TRO EXT

ACA ROB

ACA VENU

A V BIS

ACA CAR

MES AMER

K SER CUR

ANU FISS

ANU SP

ASC ECA

ASC OVAL

ASC SP

A.SP HERR

ASP PRIO

ASP SP

ASP MULT

AS_OPSIS

BRA ANGU

BRA CALY

BRA HAVA

BRA PATU

BRA QUAD

BRA URCE

BRAC SP

CEPHA SP
Orthocyclops sp.

Paracyclops sp.

Tropocyclops sp.

Ectocyclops polyspinosus

Eucyclops serrulatus

Eucyclops neomacriroides

Eucyclops macruroides denticulatus

Eucyclops prionophorus

Tropocyclops prasinus prasinus

Tropocyclops extensus

Acanthocyclops robustus

Acanthocyclops venustoides

Acanthocyclops venustoides bispinosus

Acanthocyclops carolinianus

Mesocyclops americanus

Keratella semulata curvicomis

Anuracopsis fissa

Anuraeopsis sp.

Ascomorpha ecaudis

Ascomorpha ovalis

Ascomorpha sp.

Asplanchina herricki

Asplanchna priodonta

Asplanclina sp.

Asplanchnopsis multiceps

Asplanchnopsis sp.

Brachionus angularis

Brachionus calyciflorus

Brachionus havaniensis

Brachionus patulus

Brachionus quadridentata

Brachionus urceolaris

Brachionus sp.

Cephalodella sp. 
Table 2 (cont'd.)

519

520

521

522

523

524

525

526

527

528

529

530

531

532

533

534

535

536

537

538

539

540

541

542

543

544

545

546

547

548

549

550

551

552
CHRO OVA

CHRO SP

COL MUT

COL SP

COLU UNC

COLU SP

CONO COE

CONO EXI

CONO NAT

CONO SP

CON HIPP

CON UNI

CON SP

EUCHL SP

FIL LONG

FIL TERM

FIL SP

GAS HYPT

GAS STYL

GAS SP

HEX SP

KEL BOST

KEL LONG

KEL SP

KER COCH

KER CRAS

KER EARL

KER HIEM

KER QUAD

KER TAUR

KER TEST

KER SP

LEC LIGO

LEC LUNA
Cliromogaster ovalis

Chromogaster sp.

Collotheca mutabilis

Collotheca sp.

Colurella uncinata

Colurella sp.

Conochiloides coenobasis

Conochiloides exiguus

Conochiloides natans

Conochiloides sp.

Conochilus hippocrepis

Conochilus uniconis

Conochilus sp.

Euchlanis sp.

Filinia longiseta

Filinia teminalis

Filinia sp.

Gastropus hyptopus

Gastropus stylifer

Gastropus sp.

Hexarthra sp.

Kellicottia bostoniensis

Kellicottia longispina

Kellicottia sp.

Keratella cochlearis

Keratella crassa

Keratella earlinae

Keratella hiemalis

Keratella quadrata

Keratella taurocephala

Keratella testudo

Keratella sp.

Lecane ligona

Lecane luna 
Table 2 (cont'd.)

\section{SPECIES_ID SPECIES_ABBREV SPECIES_NAME}

\begin{tabular}{|c|c|c|}
\hline 553 & LEC MIRA & Lecane mira \\
\hline 554 & LEC SIG & Lecane signifera \\
\hline 555 & LEC SP & Lecane sp. \\
\hline 556 & LEP ACUM & Lepadella acuminata \\
\hline 557 & LEP PAT & Lepadclla patella \\
\hline 558 & LEP SP & Lepadella sp. \\
\hline 559 & MONO SP & Monommata sp. \\
\hline 560 & MON BULL & Monostyla bulla \\
\hline 561 & MON LUN & Monostyla lunaris \\
\hline 562 & MON QUAD & Monostyla quadridentata \\
\hline 563 & MON SP & Monostyla sp. \\
\hline 564 & NOTH ACU & Notholca acuminata \\
\hline 565 & NOTH LAB & Notholca labis \\
\hline 566 & NOTH SQU & Notholca squamula \\
\hline 567 & NOTH SP & Notholca $s p$ \\
\hline 568 & PLA PATU & Platyias patulus \\
\hline 569 & PLA SP & Platyias sp. \\
\hline 570 & PLOE LEN & Ploesoma lenticulare \\
\hline 571 & PLOE TRI & Ploesoma tricanthum \\
\hline 572 & PLOE TRU & Ploesoma truncatum \\
\hline 573 & PLOE SP & Ploesomia sp. \\
\hline 574 & POLY DOL & Polyarthra dolichoptera \\
\hline 575 & POLY EUR & Polyarthra euryptera \\
\hline 576 & POLY MAJ & Polyarthra major \\
\hline 577 & POLY REM & Polyarthra remata \\
\hline 578 & POLY VUL & Polyarthra vulgaris \\
\hline 579 & POLY SP & Polyarthra sp. \\
\hline 580 & POM SUL & Pompholyx sulcata \\
\hline 581 & POM SP & Pompholyx sp. \\
\hline 582 & SYN OBL & Synchaeta oblonga \\
\hline 583 & SYN PEC & Synchaeta pectinata \\
\hline 584 & SYN STYL & Synchaeta stylata \\
\hline 585 & SYN SP & Synchaeta sp. \\
\hline 586 & TEST PAT & Testudinella patina \\
\hline
\end{tabular}


Table 2 (cont'd.)

TEST SP

TRIC CYL

TRIC HIP

TRIC MUL

TRIC LON

TRIC POR

TRIC ROU

TRIC SIM

TRIC SP

TRI POCI

TRI TETR

TRI SP

UNID ROT

C PUNC 1

C PUNC 2

C PUNC 3

C PUNC 4

C PUNC $P$

C PUNC

C FLAV 1

C FLAV 2

C FLAV 3

C FLAV 4

C FLAV P

C FLAV

C TRIV 1

C TRIV 2

C TRIV 3

C TRIV 4

C TRIV P

C TRIV

C AMER 1

C AMER 2

C AMER 3
Testudinella sp.

Trichocerca cylindrica

Trichocerca hippocrepis

Trichocerca multicrinis

Trichocerca longiseta

Trichocerca porcellus

Trichocerca rousscleti

Trichocerca similis

Trichocerca sp.

Trichotria pocillum

Trichotria tctractis

Trichotria sp.

Unidentified rotifer

Chaobonus punctipennis instar 1

Chaoborus punctipennis instar 2

Chaoborus punctipennis instar 3

Chaobonus punctipennis instar 4

Chaobonus punctipennis pupa

Chaoborus punctipennis

Chaobonis flavicans instar 1

Chaobonus flavicans instar 2

Chaoborus flavicans instar 3

Chaoborus flavicans instar 4

Chaoborus flavicans pupa

Chaoborus flavicans

Chaoborus trivittatus instar 1

Chaobonus trivittatus instar 2

Chaobonus trivittatus instar 3

Chaobonus trivittatus instar 4

Chaoborus trivittatus pupa

Chaoborus trivittatus

Chaobonis amcricanus instar 1

Chaobonts antericantus instar 2

Chaoborus americanus instar 3 
Table 2 (cont'd.)

\begin{tabular}{|c|c|c|}
\hline SPECIES_ID & SPECIES_ABBREV & SPECIES_NAME \\
\hline 622 & C AMER 4 & Chaobons americanus instar 4 \\
\hline 623 & C AMER P & Chaobonis americanus pupa \\
\hline 624 & C AMER & Chaoborus americanus \\
\hline 625 & C ALBA 1 & Chaoboris albatus instar 1 \\
\hline 626 & C ALBA 2 & Chaoborus albatus instar 2 \\
\hline 627 & C ALBA 3 & Chaoborus albatus instar 3 \\
\hline 628 & C ALBA 4 & Chaobonis albatus instar 4 \\
\hline 629 & C ALBA P & Chaobonus albatus pupa \\
\hline 630 & C ALBA & Chaobonis albatus \\
\hline 631 & CHAOB SP & Chaobonis sp. \\
\hline 632 & CHAO PUP & Chaoborus sp. pupa \\
\hline 633 & CHAOB II & Chaobonts sp. instar 1 \\
\hline 634 & СНАОВ I2 & Chaoboris sp. instar 2 \\
\hline 635 & CHAOB I3 & Chaobones sp. instar 3 \\
\hline 636 & CHAOB 14 & Chaobonis sp. instar 4 \\
\hline 637 & MYSIS & Mysis relicta \\
\hline 701 & PERIDIN • & Peridinium spp. \\
\hline 702 & DINOBRYON & Dinobryon spp. Colonies \\
\hline 703 & CERATIUM & Ceratium hinundinella \\
\hline
\end{tabular}


Table 3 Contents of the Z_CODE table (September 1992).

\begin{tabular}{lll}
\hline TABLE PARAMETER CODE DESCRIPTION &
\end{tabular}

Z_SAMPLE STYPE_CODE

Z_SAMPLE TECH_CODE

Z_SAMPLE XS_CODE

Z_SAMPLE $^{\cdot} \quad$ LOC_CODE
COMP1

COMP2

COMP3

DIS1

DIS2

DIS3

DIS4

DIS5

DIS6

TP

NY

BO

DH

SD

RG

KR

JC

WK

SS

QAQC1

UNREP

REG

IRREG

MSLBD

WG

DRC

CT composite of several vertical hauls at one. station

composite of vertical hauls from several stations

a single vertical haul at one station

sample from a discrete depth

composite of $>1$ station at 1 depth

composite of $>1$ discrete depth at one station

composite of $>1$ discrete depth at $>1$ station epilimnetic composite of $\mathrm{S} / \mathrm{P}$ traps

hypolimnetic composite of S/P traps

Trevor Pawson

Norm Yan

Brian O'Reilly

Dave Howell

Sheila David

Robert Girard

Kim Ralph

Jim Carbone

Bill Keller

special study

replicate sample series

sample unrepresentative of community

regular sample

irregular sampling strategy

bench sheet mislabelled

William Geiling

Dorset Research Centre

Claudiu Tudorancea 
Table 3 (cont'd.)

TABLE

PARAMETER

Z_SAMPLE STUDY_CODE

Z_SAMPLE VOLCALC_CODE

Z_COUNT CNT_TYPE_CODE

Z_COUNT

CNT_SYSTEM_CODE
CODE

APIOS

LCS

SES

YORK

1

2

3

4

5

QAQC1

QAQC2

$\mathrm{R}$

SS

Z2S1

$\mathrm{Z} 2 \mathrm{~F} 2$

Z1F1

Z1S1

DM

$\mathrm{CM}$

WG

CT

NY

RS

$\mathrm{BC}$

MP

RJ

$\mathrm{JM}$

\section{DESCRIPTION}

Acid Precipitation in Ontario study

Lakeshore Capacity Study

Sudbury Environmental Study

York University

actual w \& $w / o$ haul data

actual $w$ \& fixed $w / o$ data

assumed $100 \%$ efficiency

s/p trap vol * \# of stations

$\mathrm{s} / \mathrm{p} \mathrm{vol}{ }^{*}$ proportion of that strata

replicate count with same count protocol repeat count with different count protocol routine

special study

Zebra2, Sprules caliper \#1

Zebra2, Fowler calipers \#2

Zebra1, Fowler calipers \#1

Zebra1, Sprules caliper \#1

dissecting microscope, counts without measurements

compound microscope, counts without measurements

William Geiling

ClaudiuTudorancea

Norm Yan

Richard Strus

Bruce Cave

Mike Paylor

Roberto Jain

Judy McClellan 
Table 3 (cont'd.)

TABLE

Z_COUNT CNT_PRTCL_CODE

R1

R2

R3

R4

R5

\section{Z_COUNT}

ROTIFER_INDEX_CODE

\section{1}

2

3

4

5 .

Z_COUNT CNT_GRP_CODE

Z_COUNT OMIT_CODE

Z_CHANGE TECH_CODE

$\begin{array}{ll}\text { CRUST } & \text { count of crustacea only } \\ \text { CHAOB } & \text { count of chaoborus only } \\ \text { ROT } & \text { count of rotifers only } \\ \text { C_R } & \text { count of both crustacea \& rotifers } \\ \text { CCRA } & \text { crustacea, chaoborus, rotifers and algae } \\ \text { CCR } & \text { crustacea, chaoborus and rotifers } \\ \text { TAXON } & \text { count of } 1 \text { taxon only }\end{array}$

SWARM patch of zooplankton sampled numbers too high

DENT species entered twice on benchsheet

SSPCT suspect count

TP Trevor Pawson

NY Norm Yan entire sample counted (SES 73-79)

total count fixed at 350-400 (LCS 1975 TO 1980)

250 animals, $<50$ per taxon, $<30$ nauplii

50 animals of SP135 \& 142 counted (Plastic Lake 1988,89)

50 animals of all large zooplankton (York protocol)

rotifers are extremely abundant

rotifers are abundant

typical rotifer abundance

rotifers are rare

rotifers are extremely rare 
Table 3 (cont'd.)

$\begin{array}{lll}\text { TABLE PARAMETER CODE DESCRIPTION } & \end{array}$

\begin{tabular}{|c|c|c|c|}
\hline \multirow[t]{6}{*}{ Z_GẸAR } & \multirow[t]{6}{*}{ TYPE_CODE } & $\mathrm{C} / \mathrm{B}$ & DRC modified Clarke-Bumpus sampler \\
\hline & & $\mathrm{S} / \mathrm{P}$ & Schindler/Patalas trap \\
\hline & & NET & misc. nets \\
\hline & & PUMP & pump sampler \\
\hline & & TUBE & tube sample \\
\hline & & BOTL & sampling bottle e.g., Van Dorn \\
\hline \multirow[t]{2}{*}{ Z_REMOVE } & \multirow[t]{2}{*}{ TECH_CODE } & TP & Trevor Pawson \\
\hline & & NY & Norm Yan \\
\hline \multirow[t]{4}{*}{ Z_SUMMARY } & \multirow[t]{4}{*}{ W_CODE } & ZEB & $\begin{array}{l}\text { biomass from measured animals in that } \\
\text { sample }\end{array}$ \\
\hline & & RLWR1 & $\begin{array}{l}\text { measured lengths for that lake in other } \\
\text { years }\end{array}$ \\
\hline & & RLWR2 & measured lengths from other lakes \\
\hline & & MEAN & $\begin{array}{l}\text { grand mean weight for that species from all } \\
\text { lakes }\end{array}$ \\
\hline \multirow[t]{4}{*}{ Z_SUMMARY } & \multirow[t]{4}{*}{ LWR_CODE } & Y\&M & $\begin{array}{l}\text { Yan \& Mackie 1987. CJFAS 44: } 382 \text { (for } \\
\text { sp. 135) }\end{array}$ \\
\hline & & CUL & Culver et al. 1985. CJFAS 42: 1380. \\
\hline & & SPRL & Sprules et al. pers. comm. \\
\hline & & MCAUL & MCCauley. (IBP) 1984 \\
\hline \multirow[t]{2}{*}{ Z_VOLUME } & \multirow[t]{2}{*}{ TECH_CODE } & TP & Trevor Pawson \\
\hline & & NY & Norm Yan \\
\hline \multirow[t]{3}{*}{ Z_VOLUME } & \multirow[t]{3}{*}{ TECHNIQUE_CODE } & FS & folsom splitter \\
\hline & & BBL & mixing by bubbling and pipeting \\
\hline & & STIR & mixing by figure 8 stirring and pipeting \\
\hline
\end{tabular}


Table 3 (cont'd.)

TABLE

PARAMETER

CODE

DESCRIPTION

Z_NOMENCLATURE

CHNG_CODE

NEW

a new species

SPLIT

a split of an old species

LUMP

lumping of old spp.

NAME

new name for old species

GONE

a name no longer used 


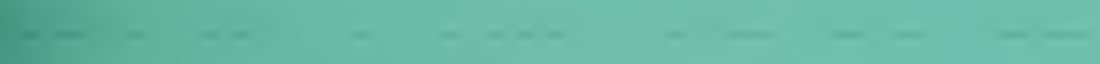


